\title{
BMJ Open Immigrant mothers and access to prenatal care: evidence from a regional population study in Italy
}

\author{
Manuela Chiavarini, ${ }^{1}$ Donatella Lanari, ${ }^{2}$ Liliana Minelli, ${ }^{1}$ Luca Pieroni, ${ }^{3}$ \\ Luca Salmasi ${ }^{3}$
}

To cite: Chiavarini M, Lanari D, Minelli L, et al. Immigrant mothers and access to prenatal care: evidence from a regional population study in Italy. BMJ Open 2016;6:e008802. doi:10.1136/bmjopen-2015008802

- Prepublication history for this paper is available online. To view these files please visit the journal online (http://dx.doi.org/10.1136/ bmjopen-2015-008802).

Received 18 May 2015 Accepted 14 January 2016

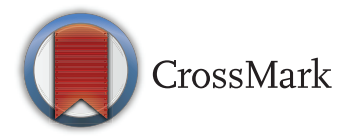

${ }^{1}$ Unit of Public Health, Department of Experimental Medicine, University of Perugia, Perugia, Italy ${ }^{2}$ Department of Medicine, University of Perugia, Piazzale Lucio Severi, Perugia, Italy ${ }^{3}$ Department of Political Science, University of Perugia, Perugia, Italy

Correspondence to Dr Luca Salmasi; luca.salmasi@unipg.it

\section{ABSTRACT}

Objectives: We addressed the question of whether use of adequate prenatal care differs between foreignborn and Italian mothers and estimated the extent to which unobservable characteristics bias results.

Setting: This study is on primary care and especially on adequate access to prenatal healthcare services by immigrant mothers.

Participants: Approximately 37000 mothers of both Italian and foreign nationality were studied. Data were obtained from the Standard Certificate of Live Birth between 2005 and 2010 in Umbria.

Results: Estimates from the bivariate probit model indicate that immigrant mothers are three times more likely to make fewer than four prenatal visits $(O R=3.35)$ and 1.66 times more likely to make a late first visit $(\mathrm{OR}=1.66)$. The effect is found to be strongest for Asian women.

Conclusions: Standard probit models lead to underestimation of the probability of inadequate use of prenatal care services by immigrant women, whereas bivariate probit models, which allow us to consider immigrant status as an endogenous variable, estimated ORs to be three times larger than those obtained with univariate models.

\section{INTRODUCTION}

A large body of epidemiological literature in Europe has established that the amount of prenatal care (PNC) accessed by pregnant women of foreign origin is usually lower than that of native women. ${ }^{2}$ These studies highlighted how mothers belonging to ethnic minorities usually tend to delay access and make fewer visits. For example, all non-Dutch mothers started PNC significantly later than Dutch women. ${ }^{3}$ Such disparities in maternal healthcare have also been found in Norway and Sweden, ${ }^{4}{ }^{5}$ Switzerland ${ }^{6}$ and Italy. ${ }^{7}$ In particular, foreigners have reported problems in accessing the national healthcare system which are related to lack of language proficiency and cultural assimilation. ${ }^{9}$ The

\section{Strengths and limitations of this study}

- We test whether unobservable factors are responsible for biasing the estimate of the effect of migration on prenatal care (PNC) use and provide unbiased estimates of the effect of migration on PNC use.

- We use a bivariate probit model, which allows us to estimate the effect of a binary endogenous variable on the outcome of interest.

- It is of crucial importance to provide estimates that are as close as possible to causal effects for the design of policies aimed at reducing inequalities in access to PNC services.

- Correlations could lead us to waste resources on potentially ineffective actions.

- It is difficult to find valid experimental settings on migration changes, thus our results rely on the assumptions of the bivariate probit model to identify and correct for endogeneity.

Italian Health Service (IHS) is based on the principle of universal coverage.

The IHS is financed by general taxation and has decentralised governance, ensuring that national guidelines and set targets are implemented across the country through the power and responsibility of 19 regions and two autonomous provinces managing assigned budgets, healthcare organisation and local performance. Decentralised governance is then responsible for ensuring the delivery of PNC services by means of public and private accredited hospitals. The IHS provides universal coverage and free prenatal healthcare at the point of delivery to all Italian and EU mothers. Regardless of coverage, emergency treatment is available free or at low cost to anyone who requires it. Nevertheless, organisational, cultural, socioeconomic and individual barriers may preclude access to adequate PNC use by some vulnerable groups of the population such as immigrant women. Empirical research on this topic has shown reduced use of health 
services and lower rates of care among immigrants, a phenomenon particularly emphasised in irregular immigrants. ${ }^{11}$

Measuring inequalities in terms of adequacy of PNC use between resident and immigrant mothers is, however, a serious issue if we consider that these two groups are likely to be different in a number of observable and unobservable characteristics. Previous studies have shown that the reason for migration is often to find better living conditions. ${ }^{12}{ }^{13}$ For similar reasons, migrant women may take better care of their own and their child's health during pregnancy and infancy-for example, by more carefully following the guidelines of the WHO in terms of using PNC services. If this is the case, a simple comparison among Italian and foreigner mothers will overestimate the true difference between the two groups because the higher level of orientation toward future health would be positively correlated with the immigrant status and negatively with inadequate use of PNC.

Another problem related to self-selection into migration is represented by the fact that, if the migration process is difficult and physically demanding, only healthier people can afford migration ('healthy immigrant effect' theory). However, if the inequality level in the country of origin is much higher than that of the country of destination, it will be more likely that people located at the top of the distribution of wealth will have more incentives to remain in the country of origin. ${ }^{14}$ In this scenario, only those at the bottom of the distribution will migrate and, if we assume that wealthier people are also those with better health, we will have a negative selection of individuals into migration. In this case, the presence of individual unobservable characteristics may have the opposite effect to before. The channels through which this may happen are related to knowledge about the rules of IHS on adequate PNC use, language proficiency, and legal immigrant status. Some studies have investigated the reduced use of PNC among foreign mothers compare with natives in Italy, identifying the existence of administrative, linguistic and cultural barriers. ${ }^{11} 1516$ These unobservable factors would be correlated negatively with immigrant status and positively with inadequate PNC use and, if not accounted for, would imply underestimation of the true effect of immigrant status on inadequate PNC use.

Since the self-selection mechanisms are likely to produce an ambiguous effect on estimates of the relationship between immigrant status and inadequate use of PNC services, this study aims to contribute to the existing literature by (i) testing whether unobservable factors are responsible for biasing estimates of the effect of migration on PNC use, (ii) providing unbiased estimates of this effect, and (iii) providing an interpretation of what unobservable effects prevail. We will use a bivariate probit model, which allows us to estimate the effect of a binary endogenous variable on the outcome of interest. Following healthcare indicators for monitoring and evaluating maternal and child health in the prenatal period, ${ }^{17}$ we considered two binary indicators of adequacy and access to PNC related to number of prenatal visits and timing of first visit, which we will discuss in more detail below. Our empirical models also account for a large number of sociodemographic factors that have been found to be relevant in explaining inequalities of access to PNC.

Furthermore, since substantial evidence from previous studies indicates that the country of origin plays an important role in determining differences in PNC use, we estimate univariate and bivariate probit models on different subsamples, differentiated by country of origin of the migrant women, showing the heterogeneity of the effects of migration on inadequate PNC use. Our results confirm that the underestimation of the effects resulting from unobservable characteristics is larger in some subsamples.

\section{DATA AND METHODS \\ Data}

Our study is based on data obtained from the Standard Certificate of Live Birth (SCLB) of the Umbria region (Italy) in the period between 2005 and 2010. The corresponding Italian name of this database is Certificato di Assistenza al Parto (CeDAP). This data source provides information on the births for the entire population of Umbria. In Italy, the law requires birth certificates to be completed for all births. The SCLB data are collected by the Ministry of Health and evaluated by the National Institute of Statistics. These certificates provide information on the health, epidemiological and sociodemographic characteristics of women through the registration of birth events, including causes of mortality and possible malformations of the newborn. To ensure methodological harmonisation of the regional surveys and to obtain datasets containing comparable indicators, each participating region was required to use the same questionnaire. The midwife who attends the birth or the doctor responsible for the operational unit completes the SCLB within 10 days of the delivery. It contains epidemiological information regarding the risk factors in the pregnancy, obstetric procedures, characteristics and methods of delivery, and abnormal conditions and congenital anomalies of the newborn. We used population data from the Umbria region that merged data from each mother and her baby for a total of 37000 . SCLB coverage ranges from $98.6 \%$ in 2005 to $96.3 \%$ in 2010 , but in the years between these two dates coverage also reached $100 \%$ of births in Umbria. In 2003, Istituto Nazionale di Statisitca (ISTAT) validated SCLB data at the Italian level for the main demographic variables (ie, nationality of parents). Given the very high coverage reached in Umbria, this should not be a relevant problem.

Indicators of inadequate PNC use and covariates

We followed the healthcare indicators recommended by the $\mathrm{WHO}^{17}$ for monitoring and evaluating maternal and 
child health in the perinatal period, which includes those related to the management of subfertility and the care of preterm infants, and considered two binary indicators of access to PNC from the SCLB:

1. Number of prenatal visits: low number of prenatal medical visits (LPVs) (below 4) and standard number of prenatal visits (at least 4). Although there is no consensus about the optimal number of prenatal visits, we refer to arguments in the prevalent literature to justify the choice of the threshold of four recommended prenatal visits. ${ }^{18}$

2. Timing of first visit: late first visit (after more than 12 weeks) (LFV) and regular timing of first visit (less than 12 weeks). This indicator is the one recommended in the epidemiological literature. ${ }^{19-21}$

In order to test the difference in use of PNC between immigrant and Italian women, we defined a binary variable, which assigns ' 1 ' to mothers born outside of Italy and ' 0 ' to those born in Italy. It is worth noting that our definition of immigration does not distinguish between foreign-born women with or without Italian nationality or between regular and irregular immigrants.

Descriptive statistics for the two PNC outcomes of interest, conditional on country of birth, are listed in table 1 . We observe that women attending the first visit sooner tend to be Italian $(95.6 \%$ make the first visit before the 12th gestational week) rather than immigrants (about 84.8\%). The percentage is lowest for Asian mothers, only $77 \%$ of whom make the first visit before the 12th gestational week. Focusing on the number of visits, we can see how only $5 \%$ of Italian women make fewer than four visits, whereas more than $17 \%$ of immigrant mothers do not make at least four visits, and, as previously, the figure is even higher for Asian women.

In order to analyse descriptively spatial differences in the use of PNC services among Italian and immigrant women, we present in figure 1 a map of the Umbria region, which shows the percentages of mothers making a low number of visits (LPV) or a late first visit (LFV). The darkest areas in the map represent the municipalities with lower access to PNC services, and lighter ones represent those with higher rates. This figure highlights that there are evident disparities in the use of PNC services between Italian and foreign mothers, especially in the south-western area of Umbria.

We considered as additional control variables a set of individual-level variables: age, with four categories, $<20$, 20-29, 30-39 and >39 (reference category 20-29); marital status, with two categories, married, unmarried (reference category married); education, classified according to the International Standard Classification of Education (ISCED), 'low' (not more than 8 years of education), 'medium' (9-13 years) and 'high' ( $>13$ years) (the latter was used as the reference category); employment status, classified into five categories, self-employed or white collar workers, blue-collar workers, and unemployed, looking for a first job, and students or housewives (reference category self-employed or white collars). We also examined the impact of pregnancy factors on preterm birth by including women with previous pregnancies (pluriparous women, category 1+; absence of previous pregnancies, 0) (the last category is taken as the reference category). We also included some father's characteristics: nationality, with two categories, Italy and foreign born (reference category Italy); age, education and occupation, which contain the same modalities as those described for mother's characteristics. We do not have in our database a measure for mother's health, but we can control indirectly for this factor, given that, as is well known from the medical and economic literature, socioeconomic (ie, occupation) condition and education correlate highly with health status. Descriptive statistics of all covariates conditional to PNC outcomes are listed in table 1.

\section{Statistical methods}

In order to analyse the relationship between PNC access equality $(\mathrm{Y})$ and immigration, controlling for a set of observable confounders, we first use a univariate probit model. This model is then estimated including municipal-level fixed effects (FE-Probit), which account for the influence of territorial differences. In fact, inadequate access may also be influenced by territorial differences unrelated to immigrant status, such as the distance or accessibility from the municipality of residence to health facilities. Including municipal-level fixed effects, we control for these differences and provide reliable estimates. For the sake of simplicity, we omit time effects and write the model as follows:

$$
\begin{aligned}
\operatorname{Pr}\left(\mathrm{Y}_{\mathrm{i}, \mathrm{h}}\right. & =1 \mid \mathrm{X}) \\
& =\beta_{0}+\beta_{1} \mathrm{I}_{\mathrm{i}}+\sum_{\mathrm{k}=2}^{\mathrm{K}_{1}} \beta_{\mathrm{k}} \mathrm{X}_{\mathrm{ki}}+\sum_{\mathrm{k}=\mathrm{K}_{1}+1}^{\mathrm{K}_{2}} \beta_{\mathrm{k}} \mathrm{M}_{\mathrm{k}}+\varepsilon_{\mathrm{i}}
\end{aligned}
$$

where $Y_{h}$ (with $h=1,2$ ) represents the two outcomes under analysis, LPV and LFV, and $\mathrm{I}_{\mathrm{i}}$ is a dummy variable equal to 1 if the mother is born outside Italy and 0 otherwise. The matrix of covariates, $\mathrm{X}_{\mathrm{ki}}$, contains the variables at the individual level already described in the previous subsection, and five time dummies. Under this specification, the set of dummy variables, $\mathrm{M}_{\mathrm{k}}$, mimics the influence of unobservable characteristics of the municipal residence of the woman.

Since we are interested in identifying the effect of immigration on the use of PNC services-which may depend on individual unobservable characteristics-we propose a recursive bivariate probit model. These models allow us to estimate the effect of an endogenous binary variable (foreign-born mothers versus natives) on binary outcomes, in the presence of unobservable characteristics. $^{22}{ }^{23}$ In fact, unobserved factors behind migration are assumed to lead to differences in PNC use between immigrants and Italian mothers. As a general 
Table 1 Descriptive statistics

\begin{tabular}{|c|c|c|c|c|c|c|c|c|c|}
\hline \multirow[b]{3}{*}{ Variable } & \multirow[b]{3}{*}{ Category } & \multirow{2}{*}{\multicolumn{2}{|c|}{$\frac{\text { Number of visits }}{\geq 4}$}} & \multirow{2}{*}{\multicolumn{2}{|c|}{$<4$}} & \multirow{2}{*}{\multicolumn{2}{|c|}{$\frac{\text { First visit }}{<12 \text { weeks }}$}} & \multirow{2}{*}{\multicolumn{2}{|c|}{$\geq 12$ weeks }} \\
\hline & & & & & & & & & \\
\hline & & $\mathbf{n}$ & Per cent & $\bar{n}$ & Per cent & $\mathrm{n}$ & Per cent & $\mathbf{N}$ & Per cent \\
\hline \multirow[t]{6}{*}{ Mother's country of birth } & Italian & 37060 & 0.96 & 1454 & 0.04 & 36710 & 0.95 & 1902 & 0.05 \\
\hline & Eastern Europe & 5544 & 0.88 & 773 & 0.12 & 5344 & 0.84 & 1025 & 0.16 \\
\hline & Maghreb countries & 1883 & 0.83 & 396 & 0.17 & 1882 & 0.82 & 423 & 0.18 \\
\hline & South America & 823 & 0.89 & 97 & 0.11 & 784 & 0.85 & 140 & 0.15 \\
\hline & Asia & 421 & 0.77 & 128 & 0.23 & 433 & 0.77 & 131 & 0.23 \\
\hline & Other & 1708 & 0.88 & 231 & 0.12 & 1705 & 0.87 & 255 & 0.13 \\
\hline \multirow[t]{4}{*}{ Mother's age } & $\leq 20$ & 1094 & 0.87 & 168 & 0.13 & 1022 & 0.80 & 253 & 0.20 \\
\hline & 20-29 & 14936 & 0.92 & 1275 & 0.08 & 14657 & 0.90 & 1690 & 0.10 \\
\hline & 30-39 & 28092 & 0.95 & 1357 & 0.05 & 27918 & 0.94 & 1684 & 0.06 \\
\hline & $>39$ & 3318 & 0.95 & 174 & 0.05 & 3261 & 0.93 & 250 & 0.07 \\
\hline \multirow[t]{3}{*}{ Mother's education } & High & 12543 & 0.96 & 539 & 0.04 & 12516 & 0.95 & 602 & 0.05 \\
\hline & Medium & 24206 & 0.95 & 1289 & 0.05 & 23849 & 0.93 & 1729 & 0.07 \\
\hline & Low & 10691 & 0.89 & 1297 & 0.11 & 10493 & 0.87 & 1544 & 0.13 \\
\hline \multirow[t]{5}{*}{ Mother's occupation } & White collar & 6238 & 0.96 & 275 & 0.04 & 6206 & 0.95 & 324 & 0.05 \\
\hline & Blue collar & 25092 & 0.96 & 1013 & 0.04 & 24891 & 0.95 & 1294 & 0.05 \\
\hline & Unemployed & 4562 & 0.90 & 481 & 0.10 & 4459 & 0.88 & 609 & 0.12 \\
\hline & Student & 689 & 0.91 & 66 & 0.09 & 669 & 0.88 & 90 & 0.12 \\
\hline & Home maker & 10860 & 0.89 & 1281 & 0.11 & 10632 & 0.87 & 1560 & 0.13 \\
\hline \multirow[t]{2}{*}{ Mother's marital status } & Married & 36498 & 0.94 & 2416 & 0.06 & 36202 & 0.93 & 2827 & 0.07 \\
\hline & Unmarried & 10942 & 0.94 & 709 & 0.06 & 10656 & 0.91 & 1049 & 0.09 \\
\hline \multirow[t]{2}{*}{ Parity } & 0 & 28556 & 0.95 & 1526 & 0.05 & 28179 & 0.93 & 1992 & 0.07 \\
\hline & $1+$ & 18884 & 0.92 & 1625 & 0.08 & 18679 & 0.91 & 1884 & 0.09 \\
\hline \multirow[t]{2}{*}{ Father's country of birth } & Italian & 8262 & 0.85 & 1483 & 0.15 & 8058 & 0.82 & 1784 & 0.18 \\
\hline & Foreign born & 39178 & 0.96 & 1550 & 0.04 & 38800 & 0.95 & 2092 & 0.05 \\
\hline \multirow[t]{3}{*}{ Father's age } & $\leq 20$ & 7115 & 0.92 & 604 & 0.08 & 6929 & 0.89 & 896 & 0.11 \\
\hline & 20-29 & 29421 & 0.95 & 1567 & 0.05 & 29176 & 0.93 & 2076 & 0.07 \\
\hline & $>30$ & 10904 & 0.94 & 648 & 0.06 & 10753 & 0.92 & 904 & 0.08 \\
\hline \multirow[t]{3}{*}{ Father's education } & High & 8141 & 0.95 & 391 & 0.05 & 8152 & 0.95 & 418 & 0.05 \\
\hline & Medium & 24497 & 0.95 & 1257 & 0.05 & 24158 & 0.93 & 1721 & 0.07 \\
\hline & Low & 14802 & 0.92 & 1364 & 0.08 & 14548 & 0.89 & 1737 & 0.11 \\
\hline \multirow[t]{5}{*}{ Father's occupation } & White collar & 7984 & 0.97 & 263 & 0.03 & 7966 & 0.95 & 382 & 0.05 \\
\hline & Blue collar & 37752 & 0.95 & 2034 & 0.05 & 37243 & 0.92 & 3201 & 0.08 \\
\hline & Unemployed & 1483 & 0.90 & 166 & 0.10 & 1431 & 0.84 & 267 & 0.16 \\
\hline & Student & 176 & 0.93 & 13 & 0.07 & 172 & 0.89 & 21 & 0.11 \\
\hline & Home maker & 45 & 0.90 & 5 & 0.10 & 46 & 0.90 & 5 & 0.10 \\
\hline
\end{tabular}

mechanism, a better attitude of migrant pregnant women towards their own and their child's future, which in turn is transferred to the use of PNC during pregnancy, may underestimate the true differences between native and foreign women. Formally, the bivariate probit specification is as follows:

$$
\begin{aligned}
& \operatorname{Pr}\left(\mathrm{Y}_{\mathrm{i}, \mathrm{k}}=1 \mid \mathrm{X}\right)=\beta_{0}+\beta_{1} \mathrm{I}_{\mathrm{i}}+\sum_{\mathrm{k}=2}^{\mathrm{K}_{1}} \beta_{\mathrm{k}} \mathrm{X}_{\mathrm{ki}}+\sum_{\mathrm{k}=\mathrm{K}_{1}+1}^{\mathrm{K}_{2}} \beta_{\mathrm{k}} \mathrm{M}_{\mathrm{k}}+\varepsilon_{\mathrm{i}, 1} \\
& \mathrm{I}_{\mathrm{i}}=\gamma_{0}+\sum_{\mathrm{k}=1}^{\mathrm{K}_{1}} \gamma_{\mathrm{k}} \mathrm{X}_{\mathrm{ki}}+\sum_{\mathrm{k}=\mathrm{K}_{1}+1}^{\mathrm{K}_{2}} \gamma_{\mathrm{k}} \mathrm{M}_{\mathrm{k}}+\varepsilon_{\mathrm{i}, 2}
\end{aligned}
$$

We assume that $\mathrm{E}\left[\varepsilon_{1}\right]=\mathrm{E}\left[\varepsilon_{2}\right]=0$, $\operatorname{Var}\left[\varepsilon_{1}\right]=\operatorname{Var}\left[\varepsilon_{2}\right]=1$ and that $\operatorname{Cov}\left[\varepsilon_{1}\right]=\operatorname{Cov}\left[\varepsilon_{2}\right]=\mathrm{r}$. If $\mathrm{r}$ is significantly different from zero, we conclude in favour of the presence of endogeneity between immigration and PNC use, and justify the use of the bivariate specification. On the other hand, if $\mathrm{r}$ is equal to 0 , the univariate model is preferred. The sign of $r$ indicates whether the standard probit estimates are biased downward or upward.

In order to identify the immigration effect, the exclusion restriction on the exogenous variables must hold. We follow Woodward ${ }^{24}$ and estimate the bivariate model assuming that they are affected by a different set of variables and, in particular, we exclude father's education and occupation from outcome equations. The exclusion of these variables was prompted by the evidence that, in preliminary estimates, they were found not to affect the probability of inadequate PNC use, in terms of both LFV and LPV and, at the same time, they were significant, especially father's education, in explaining immigration. 

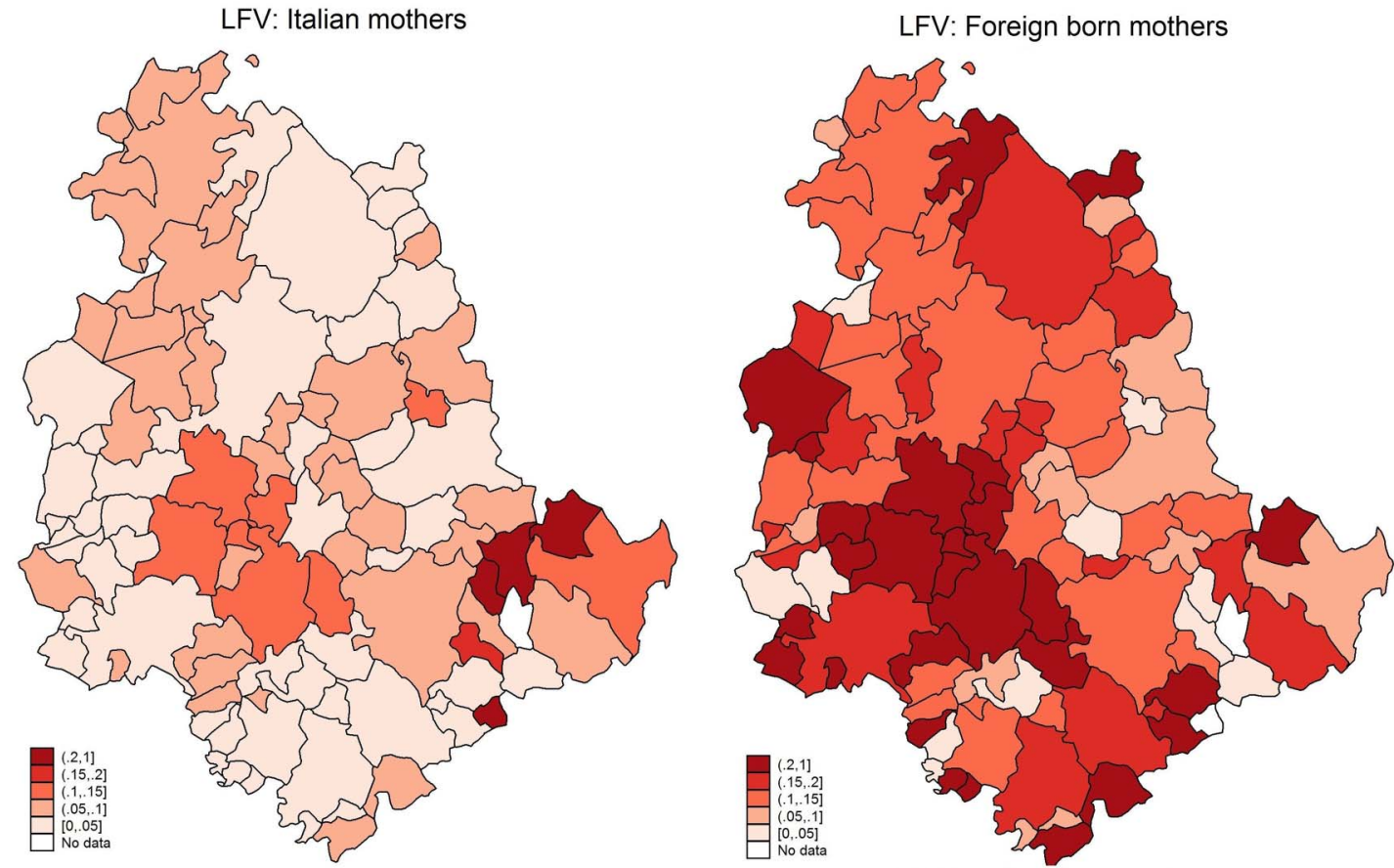

Figure 1 Territorial disparities of prenatal care (PNC) utilisation in the Umbria region. LPV, fewer than four prenatal visits; LFV, late first visit.

\section{RESULTS}

Effect of immigration on PNC use

In this subsection, we discuss the results on the effect of migration on PNC use. Table 2 lists the estimated ORs when the dependent variable is LPV. Estimates of univariate probit models with and without municipal-level fixed effects are reported in the first and second column, and columns 3 and 4 list those obtained under the bivariate specification without (Bi-Probit) and with (Bi-Probit:FE) municipal-level fixed effects. As we can see, the univariate probit model estimates a significant difference in the use of PNC services between Italian and immigrant women when we consider LPV as outcome. The group of immigrant mothers is $24 \%$ more likely to make an LPV (OR=1.24). This coefficient is robust to the inclusion of territorial dummies, meaning that the effect estimated through the univariate probit specification does not depend on territorial unobserved factors, which could be correlated with migration status and adequacy of PNC (column 2). Estimates from the 
Table 2 Prenatal care utilisation by foreign-born mothers (ORs)

\begin{tabular}{|c|c|c|c|c|}
\hline & Probit & Probit:FE & Bi-Probit & Bi-Probit:FE \\
\hline LPV & $\begin{array}{l}1.24^{\star * *} \\
(0.052)\end{array}$ & $\begin{array}{l}1.23^{\star \star \star} \\
(0.053)\end{array}$ & $\begin{array}{l}3.35^{\star \star \star} \\
(0.539)\end{array}$ & $\begin{array}{l}3.07^{\star \star \star} \\
(0.583)\end{array}$ \\
\hline 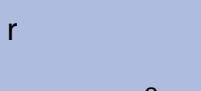 & & & $\begin{array}{l}-0.53^{* * *} \\
(0.000)\end{array}$ & $\begin{array}{l}-0.48^{\star * *} \\
(0.001)\end{array}$ \\
\hline Pseudo- $R^{2}$ & 0.08 & 0.09 & & \\
\hline LFV & $\begin{array}{l}1.27^{* \star *} \\
(0.053)\end{array}$ & $\begin{array}{l}1.27^{\star * \star} \\
(0.054)\end{array}$ & $\begin{array}{l}1.66^{\star \star \star} \\
(0.24)\end{array}$ & $\begin{array}{l}1.63^{\star \star *} \\
(0.235)\end{array}$ \\
\hline-5 & & & $\begin{array}{l}-0.13^{*} \\
(0.077)\end{array}$ & $\begin{array}{l}-0.12^{*} \\
(0.072)\end{array}$ \\
\hline Pseudo-R ${ }^{2}$ & 0.08 & 0.09 & & \\
\hline Observations & 37088 & 37032 & 37088 & 37088 \\
\hline
\end{tabular}

Outcomes of interest: (i) fewer than four prenatal visits (LPV) against four or more prenatal visits; (ii) late first visit (LFV) against regular timing of first visit. SDs in parentheses. Significant levels as follows: ${ }^{* \star} p \leq 0.01,{ }^{* *} p \leq 0.05,{ }^{*} p \leq 0.1$.

bivariate model reveal that there is a significant and large negative correlation between the residuals of the two equations. The $\mathrm{r}$ coefficient of the bivariate probit model is $-0.53 \quad(p=0.001)$ if we do not consider a municipal-level effect, and $-0.48 \quad(\mathrm{p}=0.000)$ with municipal-level fixed effects accounted for. The probability of LPV for immigrant mothers with respect to Italian mothers is 3.35 times higher when we do not account for fixed effects, and 3.07 when we account for fixed effects. This means that, correcting for selection effects through the bivariate probit specification, the probability of LPV for mothers of foreign origin is three times larger than that estimated under the univariate probit model.

Table 2 also lists the estimated ORs when the outcome of interest is LFV. The Probit specification (column 1) estimates an OR of 1.27, meaning that immigrant women show a higher propensity to make an LFV than Italian ones. As in the previous case, the estimated OR is not significantly influenced by the inclusion of municipal-level fixed effects. The estimated correlation between the residuals of the two equations is statistically significant, although the magnitude is much lower than for LPV. The estimates are $-0.12(p=0.047)$ accounting for fixed effects and $-0.13(\mathrm{p}=0.051)$ not accounting for fixed effects. Estimates from the bivariate probit model indicate that, even though the increase in the OR appears to be substantial, territorial fixed effects are not relevant in explaining differences in PNC use. We find that the probability of being late for the first visit is more than $60 \%$ higher for immigrant mothers than for Italian ones (respectively $\mathrm{OR}=1.66$ without fixed effects and $\mathrm{OR}=1.63$ with fixed effects), in accordance with the assumption of underestimation of the effect in the univariate probit model.

\section{Heterogeneous effects of immigration on PNC use by country of origin}

Table 3 shows estimates from the bivariate probit model with fixed effects (Bi-Probit:FE) for immigrant mothers according to their country of origin classified as: (i) Eastern Europe; (ii) Maghreb countries; (iii) South America; (iv) Asia. We excluded from the analysis mothers born in Western Europe because they are very

Table 3 ORs for low number of prenatal visits (LPV) and late first visit (LFV) of foreign-born mothers by country of origin

\begin{tabular}{|c|c|c|c|c|}
\hline & Eastern Europe & Maghreb countries & South America & Asia \\
\hline LPV & $\begin{array}{l}3.05^{\star \star *} \\
(0.481)\end{array}$ & $\begin{array}{l}2.09^{\star * *} \\
(0.294)\end{array}$ & $\begin{array}{l}1.43 \\
(0.345)\end{array}$ & $\begin{array}{l}4.58^{\star \star *} \\
(0.787)\end{array}$ \\
\hline Constant & $\begin{array}{l}0.10^{\star \star \star} \\
(0.012)\end{array}$ & $\begin{array}{l}0.11^{\star \star \star} \\
(0.014)\end{array}$ & $\begin{array}{l}0.11^{* * *} \\
(0.015)\end{array}$ & $\begin{array}{l}0.11^{\star \star \star} \\
(0.015)\end{array}$ \\
\hline r & $\begin{array}{l}-0.48^{\star * \star} \\
(0.056)\end{array}$ & $\begin{array}{l}-0.18^{\star \star} \\
(0.07)\end{array}$ & $\begin{array}{l}-0.17 \\
(0.107)\end{array}$ & $\begin{array}{l}-0.63^{\star \star \star} \\
(0.085)\end{array}$ \\
\hline Observations & 26557 & 24181 & 23078 & 22886 \\
\hline LFV & $\begin{array}{l}1.32 \\
(0.25)\end{array}$ & $\begin{array}{l}0.97 \\
(0.126)\end{array}$ & $\begin{array}{l}1.21 \\
(0.307)\end{array}$ & $\begin{array}{l}1.82^{\star \star \star} \\
(0.422)\end{array}$ \\
\hline Constant & $\begin{array}{l}0.17^{\star \star *} \\
(0.015)\end{array}$ & $\begin{array}{l}0.17^{\star * \star} \\
(0.017)\end{array}$ & $\begin{array}{l}0.19^{* \star *} \\
(0.018)\end{array}$ & $\begin{array}{l}0.18^{\star \star \star} \\
(0.018)\end{array}$ \\
\hline$r$ & $\begin{array}{l}-0.05 \\
(0.089)\end{array}$ & $\begin{array}{l}0.11 \\
(0.086)\end{array}$ & $\begin{array}{l}0.01 \\
(0.134)\end{array}$ & $\begin{array}{l}-0.21^{* *} \\
(0.075)\end{array}$ \\
\hline Observations & 26604 & 24221 & 23116 & 22926 \\
\hline
\end{tabular}


similar to Italian mothers according to culture, access to healthcare, and health status, and those born in countries with too few observations (eg, North America and Sub-Saharan countries).

Results indicate that mothers born in three out of four of the macro-areas considered have a higher probability of LPV. Our results suggest that the probability of LPV is more than four times higher $(\mathrm{OR}=4.58)$ for women from Asia than for Italian mothers. Differences in ORs are smaller for women born in Eastern Europe $(\mathrm{OR}=3.05)$ and Maghreb countries $(\mathrm{OR}=2.09)$ with respect to Italian women. In contrast, for women born in South America, no significant effects are found according to LPV. Even though the OR is 1.43 , it is not statistically significant. The significance of the residual correlations (r), which is also found to be negative in the Bi-Probit specification in this case, justifies the adoption of a bivariate specification. Again, women from Asia have the largest negative unobservable correlation between the two equations $(\mathrm{r}=-0.63)$.

Table 3 also shows estimates according to the second indicator of inadequate access to PNC, related to the timing of the first visit, LFV, by nationality of the mother according to the four macro-areas already described. Since only women from Asia show a significant delay in the timing of the first visit compared with Italian mothers $(\mathrm{OR}=1.82)$, we can conclude that they also drive the differences found in PNC use in the general model.

\section{DISCUSSION}

\section{Comparison among estimates of models}

The aim of this paper was to estimate the difference in terms of access to PNC between migrant and native women giving birth in the Italian region of Umbria in the period 2005-2010. The result of strong underlying inequalities in healthcare received during pregnancy for the population of the Umbria region is in accordance with Italian ${ }^{711}$ and other international ${ }^{2} 25$ studies, which suggests that foreign women experience a delay in their first contact with PNC services. However, when we compare estimates of different models (ie, univariate and bivariate probit models), we find a larger difference in the probability of inadequate PNC use for immigrant women. This suggests that, in univariate probit models, ORs are biased downward for both LFV and LPV. According to our initial assumptions, this confirms that the knowledge about IHS rules on adequate PNC use, language proficiency, and the condition of being a legal immigrant are the sources of unobservability in our empirical model. We conclude in favour of this assumption because we noticed that, in each bivariate specification, $r$ is negative, and along with the downward bias in the univariate probit model, implies that the unobservable factors affecting our model are correlated negatively with immigrant status, but positively with inadequate PNC use. Consistently, we found that the father's characteristics significantly explained immigration, but did not affect PNC use. This result is different from the specific literature in Italy $^{7}$ and may be explained by the different dataset used, which in our case is restricted to one administrative region, or by the fact that by including the age of father as a control in the bivariate specification, part of the unobservable heterogeneity in explaining $\mathrm{PNC}$ use is already accounted for.

Focusing on the estimates for the two outcomes analysed-number of prenatal visits and timing of first visit - the results show remarkable differences in the magnitude of ORs between probit and bivariate models. Our results suggest that, when self-selection into migration is not accounted for properly, ORs tend to be underestimated, by as much as three times in the case of LPV; however, for LFV this difference is less clear-cut. In the light of this result, informative campaigns and policy interventions to try to reduce the high levels of inequality should focus on the former indicator. This means that unobservable characteristics do affect inequality of access to PNC between migrant and native women, although they have a larger effect on the number of visits. In accordance with the common perspective, we explain this heterogeneous behaviour as an age effect, rather than by differences between immigrants and Italian mothers. ${ }^{26}$ That is, only younger mothers tend to make the first prenatal visit late, whereas older women make the visit on time irrespective of their nationality. Thus, in Umbria at least, LFV seems to be more a problem of young women than of immigrants.

Another important result of this study is that not only women of foreign origin usually receive reduced amounts of care compared with native ones, but heterogeneous effects are also found according to different countries of origin. In accordance with who analysed ethnic differences in access to health service facilities during pregnancy in Italy, ${ }^{7}$ we found that Asian mothers, and to a lesser extent Eastern European ones, are those who contribute the most to differences in access to and use of PNC services. Although it is known that Chinese women, the prevalent ethnic group within Asian women, often use forms of healthcare provided by members of their community as a substitute for formal healthcare, ${ }^{11}$ there are also barriers related to lack of language proficiency and cultural assimilation. On the other hand, the influence of cultural and linguistic barriers is also supported by international official statistics, ${ }^{27}$ which list a lower percentage of women who do not make use of PNC during pregnancy in their home country in Asia or Eastern Europe than migrant ones.

\section{Extrapolation to other contexts}

Our results should be interpreted in the light of the particular characteristics of the population studied and the nature and timing of migration. Since results of this work can be generalised, at least to the national context, it is important to bear in mind several caveats. 
First, our results consider only the country of origin to classify mothers as migrants, regardless of their legal status. This lack of information does not allow us to use our predictions outside the studied population, since regional distribution of foreign women without Italian nationality is different and this may lead to incorrect estimates. In fact, irregular immigrants undoubtedly have the highest rates of inadequate use of PNC and healthcare services, because they are afraid of being reported to the police. ${ }^{15}$

Second, we explain the finding of large differences between the univariate and bivariate probit models as a lack of knowledge about IHS rules on adequate PNC use, language proficiency, or the status of legal immigrant. Even if we control for a large set of individual sociodemographic variables, we cannot exclude the possibility that the lower utilisation rates exhibited by immigrants may have been emphasised by the cultural barriers mentioned above. ${ }^{28} 29$

Third, our results may vary with the quality of access and frequency of healthcare services available to migrant women. In recording differences between native and migrant women, it would be useful to include information about their unmet needs, which may explain the discrepancy in the pattern of healthcare use through less satisfaction with the service they receive. ${ }^{30}$ Unfortunately, there are no data for evaluating this hypothesis because no questions about satisfaction with the healthcare service were included in the survey.

\section{CONCLUSION}

Using a regional population study from Italy, we examined the different impacts of immigration on access to and adequacy of PNC compared with native women, accounting for unobservable characteristics and comparing our results with estimates generally proposed in the literature. We found evidence of a significant level of inequality in PNC use by foreign-born women. We also found evidence that the disparities between these groups of women depend on the type of healthcare outcome examined. Our results suggest that the indicator that shows the greater level of inequality between the two groups of women is the volume of PNC use (LPV). As expected, we also found a heterogeneous effect across the countries of origin of the migrant women, which is a proxy of ethnic differences in access and adequacy of use of PNC services by these subgroups. In particular, Asian women seem to drive the greater inequality in PNC use through known cultural and linguistic barriers. These results are important inputs to be considered for cost-benefit analyses of the expansion of programmes and policies for the reduction of inequalities in PNC access by migrant women, although such an analysis would require additional information beyond the data that this study can provide.

Acknowledgements We thank the participants in the International Conference on Gender and Migration: Critical Issues and Policy Implications, 11-13 May 2013, Istanbul, for their valuable comments and suggestions.
Contributors All the authors contributed to designing the structure of the study. MC and LM contributed to conceptualising the ideas of the study. MC defined the background of the study. LS performed the statistical analysis. LP described results and reviewed the manuscript. DL interpreted and discussed results. DL and LS reviewed the manuscript. LM interpreted results and also obtained funding. All authors read and approved the final version of the manuscript.

Funding This work was supported by a grant from the Public Health Department of the Umbria Region.

Competing interests None declared.

Patient consent Obtained.

Ethics approval Ethics committee of the Hospital of Perugia.

Provenance and peer review Not commissioned; externally peer reviewed.

Data sharing statement No additional data are available.

Open Access This is an Open Access article distributed in accordance with the Creative Commons Attribution Non Commercial (CC BY-NC 4.0) license, which permits others to distribute, remix, adapt, build upon this work noncommercially, and license their derivative works on different terms, provided the original work is properly cited and the use is non-commercial. See: http:// creativecommons.org/licenses/by-nc/4.0/

\section{REFERENCES}

1. Delvaux T, Buekens $P$, Godin I, et al. Barriers to prenatal care in Europe. Am J Prev Med 2001;21:52-9.

2. Malin M, Gissler M. Maternal care and birth outcomes among ethnic minority women. BMC Public Health 2009;84:2-14.

3. Alderliesten M, Vrijkotte TG, van der Wal MF, et al. Late start of antenatal care among ethnic minorities in a large cohort of pregnant women. BJOG 2007;114:1232-9.

4. Vangen S, Stoltenberg C, Stray-Pedersen B. Complaints and complications in pregnancy: a study of ethnic Norwegian and ethnic Pakistani women in Oslo. Ethn Health 1999;4:19-28.

5. Essn B, Bödker B, Sjöberg NO, et al. Are some perinatal deaths in immigrant groups linked to suboptimal perinatal care services? BJOG 2002;109:677-82.

6. Merten S, Wyss C, Ackermann-Liebrich U. Caesarean sections and breastfeeding initiation among migrants in Switzerland. Int $J$ Public Health 2007;52:210-22.

7. Lariccia F, Mussino E, Pinnelli A, et al. Antenatal care in Italy: Differences between Italian and Foreign Women. Genus 2013;69:35-51.

8. Chiavarini M, Lanari D, Minelli L, et al. Socio-demographic determinants and access to prenatal care in Italy. BMC Health Serv Res 2014;14:174

9. Stronks K, Ravelli A, Reijneveld S. Immigrants in the Netherlands: equal access for equal needs? Epidemiol Community Health 2001;55:701-7.

10. Norredam M, Krasnik A, Sorensen T, et al. Emergency room utilization in Copenhagen: a comparison of immigrant groups and Danish-born residents. Scand J Public Health 2004;32:53-9.

11. Lauria L, Bonciani M, Spinelli $A$, et al. Inequalities in maternal care in Italy: the role of socioeconomic and migrant status. Ann Ist Super Sanita. 2013;49:209-18.

12. McKenzie DJ, Hildebrandt N. The effects of migration on child health in Mexico. J LACEA Economia 2005.

13. McKenzie D, Rapoport H. Self-selection patterns in Mexico-U.S. migration: the role of migration networks. Rev Econ Stat 2010;92:811-21.

14. Borjas GJ. Self-selection and the earnings of immigrants: reply. $A m$ Econ Rev 1990;80:305-8. http://ideas.repec.org/a/aea/aecrev/ v80y1990i1p305-08.html

15. Cacciani L, Baglio G, Rossi L, et al. Hospitalisation among immigrants in Italy. Emerg Themes Epidemiol 2006;3:1-11.

16. Fedeli U, Alba N, Lisiero M, et al. Obstetric hospitalizations among Italian women, regular and irregular immigrants in North-Eastern Italy. Acta Obstet Gynecol Scand 2010;89:1432-7.

17. WHO. WHO antenatal care randomized trial: manual for the implementation of the new model. Geneva: Wiley 2002.

18. Raatikainen K, Heiskanen N, Heinonen S. Under-attending free antenatal care is associated with adverse pregnancy outcomes. BMC Public Health 2007;7:268. 
19. EURO-PERISTAT. European Perinatal Health Report, Nber working papers, EURO-PERISTAT, 2008. http//www.europeristat.com

20. Macfarlane A, Gissler M, Bolumar F, et al. Availability of perinatal health indicators in Europe. Eur J Obstet Gynecol 2003;111:S15-32.

21. Zeitlin J. Indicators for monitoring and evaluating perinatal health in Europe. Eur J Obstet Gynecol Reprod Bio 2003;111: S5-S14.

22. Imbens GW, Wooldridge JM. Recent developments in the econometrics of program evaluation. J Econ Lit Am Econ Assoc 2009;47:5-86.

23. Angrist J, Pische J. Mostly harmless econometrics: an empiricist's companion. Princeton University Press.

24. Wooldridge JM. Econometric analysis of cross-section and panel data. Cambridge, MA: MIT Press, 2002.
25. Rowe RE, Magee H, Quigley MA, et al. Social and ethnic differences in attendance for antenatal care in England. Public Health 2008;122:1363-72.

26. Buck G, Mahoney M, Micalek A, et al. Comparison of native American births in upstate New York with other race births, 198086. Public Health Rep 1992;107:569-75.

27. WHO. Global health observatory. Geneva: World Health Organization, 2009.http://www.who.int/gho/en/

28. Buron A, Cots F, Garcia O, et al. Hospital emergency department utilization rates among the immigrant population in Barcelona, Spain. BMC Health Serv Res 2008;8:51.

29. Muennig $P$, Fahs $M$. Health status and hospital utilization of recent immigrants to New York city. Prev Med 2002;35:225-31.

30. Mussino E, Strozza S. Does citizenship still matter? Second birth risks of resident foreigners in Italy. Eur J Popul 2012;28:269-302. 